\title{
IMPLEMENTATION OF LEARNING CYCLE 7E MODEL TO PRACTICE METACOGNITIVE SKILLS ON REACTION RATE MATTER
}

\author{
Dinda Diana Rosa ${ }^{1}$, Utiya Azizah ${ }^{2 *}$ \\ ${ }^{1,2}$ Kimia, FMIPA, Universitas Negeri Surabaya \\ *Corresponding author: utiyaazizah@unesa.ac.id.
}

\begin{abstract}
The purpose of this research is to describe the implementation of Learning Cycle 7E models to practice students' metacognitive skills on reaction rate material at XI grade in SMAN 1 Taman. The research instrument used is the implementation observationsheet of Learning Cycle $7 E$ models, student activity sheet, test of metacognitive skill, and inventory metacognitive. The design of this study is "One Shoot Case Study". The results of this study indicate: (1) the implementation of Learning Cycle 7E models for four meetings are in good category and very good with an average value of 100; $100 ; 100 ; 84,38 ; 62.50 ; 78,13$; and 87.50; (2) Metacognitive skills of students on four meetings obtained good and excellent criteria of planning skills of 3.19; 3.15; 3.41; and 3.48; monitoring skills of 2.70; 3.19; 3.37; and 3.52; and evaluating skills at 2.30; 2.98; 3.32; and 3.61. (3) Metacognitive skills of students based on metacognitive inventory are in good and excellent category with average score for four meetings: planning skills of 3.05; 3.12; 3.22; and 3.44; Monitoring skills of 3.04; 3.19; 3.23; and 3.50: and evaluating skills 3.09; 3.17; 3.19; and 3.44.
\end{abstract}

Keywords: Learning Cycle 7E, metacognitive skills, reaction rate

\section{PENDAHULUAN}

Pendididikan merupakan aspek penting dan mendasar untuk menciptakan sumber daya manusia (SDM) yang berkualitas dan kompeten. Pemerintah melalui berbagai programnya bertujuan untuk meningkatkan kualitas pendidikan di Indonesia, mulai dari wajib belajar 9 tahun hingga sekarang dengan adanya kurikulum 2013 yang telah disesuaikan dengan kebutuhan siswa yang nantinya diharapkan dapat meningkatkan kualitas pendidikan dan SDM di Indonesia.

Salah satu masalah yang dihadapi dalam dunia pendidikan kita adalah lemahnya proses pembelajaran siswa, yang salah satu penyebabnya adalah kurang didorong untuk mengembangkan kemampuan [1]. Kompentensi inti yang harus dicapai dalam pembelajaran menurut Permendikbud Nomor 24 Tahun 2016 salah satunya adalah memahami, menerapkan, dan menganalisis pengetahuan faktual, konseptual, prosedural, dan metakognitif berdasarkan rasa ingin tahunya tentang ilmu pengetahuan, teknologi, seni, budaya, dan humaniora dengan wawasan kemanusiaan, kebangsaan, kenegaraan, dan peradaban terkait penyebab fenomena dan kejadian, serta menerapkan pengetahuan prosedural pada bidang kajian yang spesifik sesuai dengan bakat dan minatnya untuk memecahkan masalah [2]. Berdasarkan kompetensi inti tersebut keterampilan metakognitif perlu dilatihkan kepada siswa agar kompetensi inti dapat tercapai. Perlunya keterampilan metaognitif dilatihkan, juga diperkuat hasil temuan pra penelitian bahwa keterampilan merencanakan (planning skills) siswa hanya $27,27 \%$, keterampilan monitor (monitoring skills) 81,82\%, keterampilan mengevaluasi (evaluating skills) 24,24\% yang berarti keterampilan metakognisi siswa masih rendah.

Metakognitif sering didefinisikan sebagai berfikir tentang berfikir.Keterampilan metakognitif merupakan bagian dari berfikir tingkat tinggi (high order thinking). Keterampilan metakognitif adalah salah satu bagian dari empat macam keterampilan berfikir tingkat tinggi[3]. Metakognitif juga didefinisikan sebagai kemampuan individu untuk mengetahui dan memahami proses belajarnya dan bagaimana cara belajarnya [4]. Metakognitif mempunyai peran penting dalam keberhasilan pembelajaran, oleh karena itu mempelajari aktivitas metakognitif diperlukan untuk mengetahui bagaimana siswa mampu 
belajar dengan menerapkan strategi belajarnya sehingga prestasi belajar yang diinginkan dapat tercapai [5]. Metakognitif berkaitan dengan apa yang diketahui tentang dirinya sebagai individu yang belajar dan bagaimana mengontrol dan menyusun perilakunya. Berdasarkan pendapat-pendapat tersebut, maka metakognitif dapat membantu siswa untuk menerapkan strategi belajar sesuai dengan proses dan cara belajarnya agar tujuan belajar dapat tercapai [6]. Keterampilan metakognitif didefinisikan sebagai proses siswa merencanakan, memonitor, dan mengevaluasi proses dan cara belajarnya [7].

Keterampilan metakognitif membantu siswa untuk mengkonstruksi sendiri pengetahuan yang diperoleh menjadi pengetahuan yang bermakna, sedangkan pengetahuan yang diperoleh melalui proses pemberitahuan akan menjadi pengetahuan yang kurang bermakna. Agar dapat mencapai hal tersebut, diperlukan pendekatan dan inovasi dalam kegiatan pembelajaran yang tepat.Kurikulum 2013 menerapkan pendekatan ilmiah (saintifik) dalam pembelajaran.

Pendekatan saintifik dalam pembelajaran perlu diperkuat dengan menerapkan model pembelajaran berbasis penyingkapan/penelitian meliputi cara berpikir, sikap, dan langkah-langkah kegiatan ilmiah untuk memperoleh produk-produk kimia, mulai dari menemukan masalah, mengumpulkan fakta-fakta terkait masalah, membuat asumsi, mengendalikan variabel, melakukan observasi, melakukan pengukuran, melakukan inferensi memprediksi, mengumpulkan dan mengolah data hasil observasi/pengukuran, serta menyimpulkan dan mengomunikasikan.

Salah satu model pembelajaran berbasis penemuandankonstruktivisadalahmodel pembelajaran Learning Cycle 7E, karena dalam sintaks pembelajaran Learning Cycle $7 E$ mengarahkan siswa menemukan konsep, hukum dan teori serta menerapkan dan menjelaskan contoh penerapan konsep yang telah dipelajari.Model ini cocok diterapkan untuk materi pelajaran yang bersifat hafalan, perhitungan, eksperimen, pemahaman materi, dan materi pelajaran yang berhubungan dengan kehidupan sehari-hari [8]. Model pembelajaran ini menyarankan agar proses pembelajaran dapat melibatkan siswa dalam kegiatan belajar yang aktif sehingga terjadi proses asimilasi, akomodasi, dan organisasi dalam struktur kognitif siswa. Einsekraft mengembangkan siklus belajar mulai dari Learning cycle $3 E$ ke 5-E sampai 7-E meliputi elicit, engage, explore, explain, elaborate, evaluate, dan extend [9].

Kimia merupakan salah satu mata pelajaran yang termasuk sains. Menurut Permendikbud no. 24 tahun 2016 menyatakan bahwa kimia memiliki karakteristik yaitu sebagai pengetahuan faktual, konseptual, dan prosedural. Salah satu materi dalam mata pelajaran kimia adalah laju reaksi. Karakteristik materi laju reaksi berdasarkan kompetensi dasar (KD) yang harus dicapai siswa yaitu 3.6 Menjelaskan faktor-faktor yang memengaruhi laju reaksi menggunakan teoritumbukan, 3.7 Menentukan orde reaksi dan tetapan laju reaksi berdasarkan data hasil percobaan, 4.6 Menyajikan hasil penelusuran informasi cara-cara pengaturan dan penyimpanan bahan untuk mencegah perubahan fisika dan kimia yang tak terkendali, dan 4.7 Merancang, melakukan, dan menyimpulkan serta menyajikan hasil percobaan faktor-faktor yang mempengaruhi laju reaksi dan orde reaksi [2].Berdasarkan KD tersebut, maka pada pembelajaran laju reaksi siswa memerlukan perencanaan yang matang dalam penelusuran informasi terkait materi dan mengevaluasi proses pembelajarannya. Berdasarkan uraian diatas maka akan dilakukan penelitian untuk mengetahui pengaruh metode Learning Cycle $7 E$ dalam melatihkan keterampilan metakognitif siswa.

\section{METODE}

Jenis penelitian yang digunakan adalah penelitian pre-eksperimen dengan desain One Shoot Case Study. Sasaran penelitian ini yaitu siswa kelas XI MIA 3 di SMAN 1 Taman. Penelitian dilaksanakan pada semester gasal 2016-2017 selama empat kali pertemuan. Penelitian ini menggunakan perangkat pembelajaran meliputi silabus, Rencana Pelaksanaan Pembelajaran (RPP), Lembar Kerja Siswa (LKS) yang diadaptasi dari Rofi'ah dan Azizah [10]. Instrumen penelitian yang digunakan meliputi lembar keterlaksanaan model pembelajaran Learning Cycle $7 E$, lembar tesketerampilan 
metakognitif, dan inventori keterampilan metakognitif.

Penelitian ini menggunakan metode observasi, tes, dan angket. Metode observasi digunakan untuk mengetahui keterlaksanaan model pembelajaran Learning Cycle $7 E$ dan aktivitas siswa, metode tes untuk melatihkan dan mengetahui keterampilan metakognitif siswa, dan metode angket untuk mengetahui respon siswa terhadap kegiatan pembelajaranmenggunakaninventoriketerampi lanmetakognitif.

Datapengamatan keterlaksanaan model pembelajaran learning Cycle 7Edigunakan untuk menganalisis keterlaksanaan model pembelajaran Learning Cycle $7 E$ dengan cara memberikan tanda checklist sesuai dengan rubrik penilaian pada setiap fase.

Data aktivitas siswa digunakan untuk mengetahui aktivitas keterampilan metakognitif siswa selama pembelajaran. Data aktivitas siswa diperoleh dengan cara memberikan tanda checklist pada kolom menit untuk aktivitas yang terjadi selama kegiatan pembelajaran. Analisis aktivitas siswa mendukung data keterlaksanaan model pembelajaran Learning Cycle $7 E$.

Data keterampilan metakognitif siswa diperoleh melalui tes keterampilan metakognitif diberikan kepada setiap akhir pembelajaran dan dinilai berdasarkan rubrik penilaian yang telah dibuat. Nilai keterampilan metakognitif dihitung dengan menggunakan rumus:

$$
\text { Nilai }=\frac{\text { skor yang diperoleh }}{\text { skor maksimal }} \times 4
$$
dikategorikan sebagai berikut:

Tabel 1 Konversi nilai aktivitas keterampilan metakognitif

\begin{tabular}{lc}
\multicolumn{2}{c}{ metakognitif } \\
\hline Nilai yang Diperoleh & Kriteria \\
\hline $0,00-1,00$ & Tidak Baik \\
$1,10-2,00$ & Cukup Baik \\
$2,10-3,00$ & Baik \\
$3,10-4,00$ & Sangat Baik \\
\hline
\end{tabular}

Nilai keterampilan metakognitif siswa didukung dengan data inventori metakognitif yang diberikan kepada siswa setiap pertemuan. Interpretasi nilai inventori metakognitif siswa disajikan pada tabel 2.
Tabel 2 Interpretasi Skor Inventori Metakognitif

\begin{tabular}{lcc}
\hline \multirow{2}{*}{ Kriteria } & \multicolumn{2}{c}{ Skor } \\
\cline { 2 - 3 } & $\begin{array}{c}\text { Pernyataan } \\
\text { Negatif }\end{array}$ & $\begin{array}{c}\text { Pernyataan } \\
\text { Positif }\end{array}$ \\
\hline Tidak Pernah & 4 & 1 \\
Kadang- & 3 & 2 \\
kadang & & \\
Sering & 2 & 3 \\
Selalu & 1 & 4 \\
\hline
\end{tabular}

Selanjutnya data inventori yang diperoleh dikonversikan ke dalam beberapa kategori sebagai berikut:

Tabel 3 Kategori Penilaian Inventori Metakognitif

\begin{tabular}{rc}
\hline Skala & Kriteria \\
\hline $1,00-1,99$ & Kurang \\
$2,00-2,99$ & Cukup \\
$3,00-3,49$ & Baik \\
$3,50-4,00$ & Sangat Baik \\
\hline
\end{tabular}

\section{HASILDAN PEMBAHASAN}

Data yang diperoleh dari penelitian yang telah dilakukan meliputi: keterlaksanaan model pembelajaran Learning Cycle $7 E$, aktivitas siswa,dan keterampilan metakognitif siswa.

Data pengamatan keterlaksanaan model pembelajaran Learning Cycle 7Edisajikan pada Gambar 1.

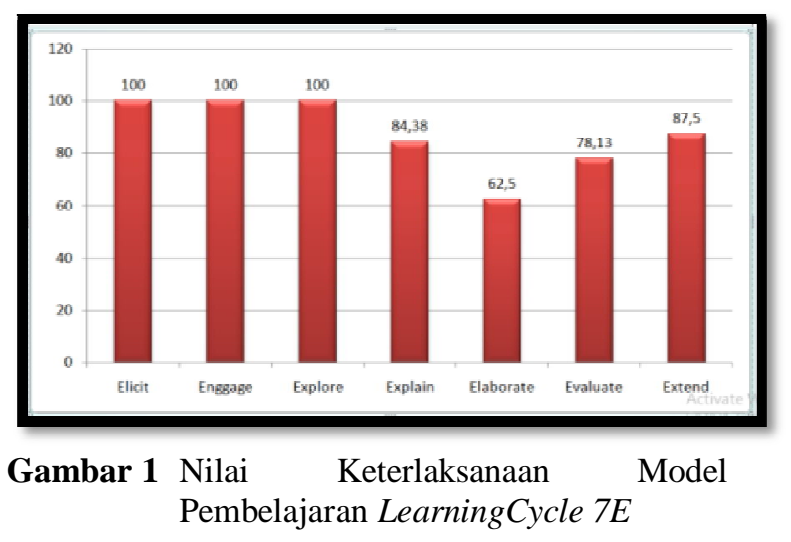

Data aktivitas siswa menunjukkan aktivitas keterampilan metakognitif siswa selama empat kali pertemuan meliputi, menuliskan apa yang diketahui dan menghubungkan antara fenomena dengan materi yang akan dipelajari (Planning Skills atau $\mathrm{P}$ ), menuliskan penjelasan terkait materi pada fase explain (monitoring skills atau M1), 
mereview hasil praktikum dengan menuliskan hasil pengamatan dan menganalisis data (monitoring skills atau M2), melakukan refleksi terhadap strategi belajar dengan mengerjakan soal dan menghubungkan antar konsep (evaluation skills atau E1), dan menuliskan kesimpulan materi (evaluation skills atau E2). Data aktivitas siswa disajikan pada Gambar2.

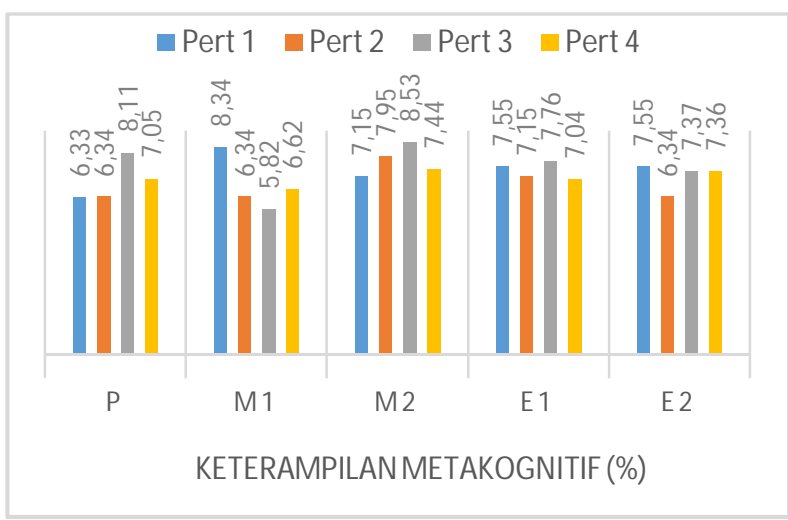

Gambar 2 Data aktivitassiswa

Berdasarkan Gambar 1 dan Gambar 2 dapat diilustrasikanbahwapada fase elicit selama empat kali pertemuan, guru telah berusaha mendatangkan pengetahuan awal siswa [9]. Pada fase elicit siswa dilatihkan keterampilan merencanakan (planning skills) yaitu berfikir dan menulis apa yang diketahui dan tidak diketahui dan menuliskan apa secara rinci informasi yang diperoleh.Pada fase elicit aktivitas siswa yang muncul yaitu siswa menuliskan apa yang diketahui dengan menjawab pertanyaan yang ada pada LKS setelah guru memberikan pertanyaan tentang konsep reaksi molaritas dan pengenceran, dan hubungan antara fenomena dengan materi yang akan dipelajari yang ada pada LKS.

Pada fase enggage, guru memperoleh nilai rata-rata keterlaksanaan model pembelajaran yaitu 100.Fase ini bertujuan untuk mendapatkan perhatian siswa, mendorong kemampuan berfikirnya dan membantu siswa mengakses pengetahuan awal yang dimilikinya [12]. Pada fase explore, guru memperoleh nilai rata-rata keterlaksanaan model pembelajaran selama empat kali pertemuan yaitu 100. Dalam fase ini, siswa diberikan kesempatan untuk mengamati data, mengisolasi variabel, merancang dan merencanakan eksperimen, membuat grafik, menafsirkan hasil, mengembangkan hipotesis serta mengatur temuan mereka [9].
Faseexplain bertujuan untuk melengkapi, menyempurnakan, dan mengembangkan konsep yang diperoleh siswa [12].Pada explain, siswa dilatihkan keterampilan metakognitif monitoringskillsyaitu meriview hasil tes dan memecahkan masalah tambahan.Aktivitas siswa yang muncul pada fase ini. Pada fase elaborate membawa siswa menerapkan simbol, definisi, konsep, dan keterampilan pada permasalahan berkaitan dengan contoh dari materi yang dipelajari [9].Pada fase elaborate, siswa dilatih keterampilan metakognitif memantau (monitoring skils) meliputi meriview hasil tes dan memecahkan masalah tambahan.Aktivitas siswa yang muncul pada fase ini yaitu meriview hasil praktikum dengan menuliskan hasil pengamatan dan menganalisis data dengan menghubungkan faktor yang mempercepat laju reaksi dengan teori tumbukan (monitoring skills).

Pada fase evaluate ada dua hal yang ingin diketahui pada kegiatan belajar yaitu: a) pengalaman belajar yang diperoleh siswa, dan b) melakukan refleksi lebih lanjut untuk pembelajaran pada konsep berikutnya [12].Pada fase evaluate, siswa dilatihkan keterampilan metakognitif mengevaluasi (evaluating skills) meliputi refleksi terhadap strategi belajar dan menilai bagaimana strategi belajar dapat diterapkan. Aktivitas siswa yang muncul selama empat kali pertemuan pada fase ini yaitu siswa melakukan refleksi terhadap strategi belajar dengan mengerjakan soal dan menghubungkan konsep yang telah dipelajari dengan konsep lain pada LKS.

Fase exend bertujuan untuk mengarahkan siswa berfikir mencari, menemukan, dan menjelaskan contoh penerapan konsep yang telah dipelajari [9].Pada extend, keterampilan metakognitif mengevaluasi (evaluating skill) dilatihkan kepada siswameliputi refleksi terhadap strategi belajar dan menilai bagaimana strategi belajar dapat diterapkan.Aktivitas siswa yang diamati yaitu refleksi terhadap strategi belajar dengan mengerjakan soal dan menghubungkan konsep yang telah dipelajari dengan konsep lain pada LKS.

Data keterampilan metakognitif siswa diperoleh melalui hasil tes keterampilan metakognitif dan didukung dengan inventori metakognitif yang diberikan setiap akhir pertemuan.Gambar 3 dan Gambar 4 adalah 
data keterampilan metakognitif siswa selama empat pertemuan.

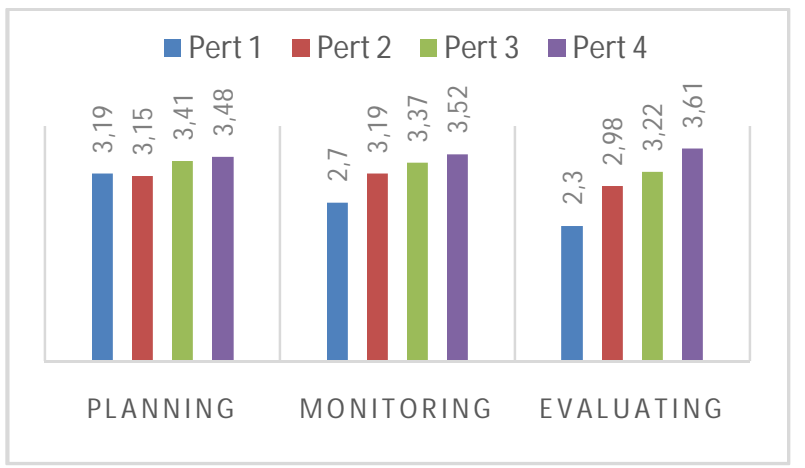

Gambar 3 Hasil tes keterampilan metakognitif siswa

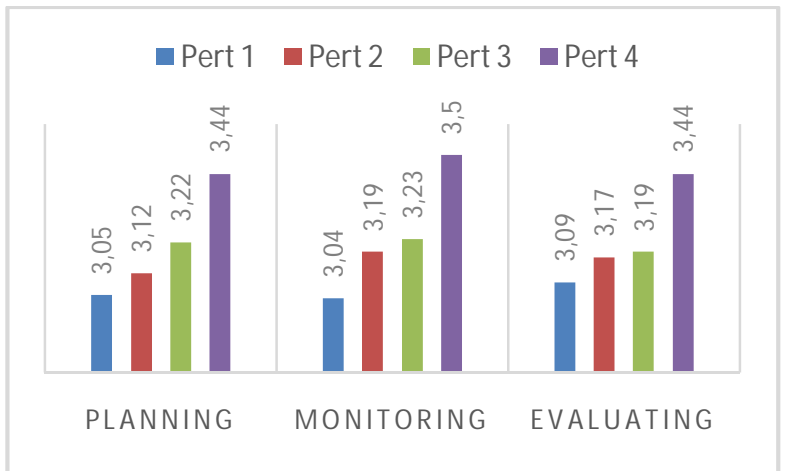

Gambar 4 Hasil Inventori keterampilan metakognitif siswa

Planning skills adalah langkah-langkah, prosedur, atau kegiatan yang melibatkan siswa dalam belajar atau menyelesaikan tugas-tugas [7]. Planning skills yang dilatihkan pada penelitian adalah berpikir dan menulis apa yang diketahui dan tidak diketahui.Tes keterampilan merencanakan tersebut dinilai dengan skor 0-3 dengan kriteria tertentu sesuai dengan rubrik penilaian. Jawaban siswa pada keterampilan planning skills ditunjukkan pada Gambar 5.

\section{a. Berdasarkan grafik diatas, tuliskan informasi yang kalian dapatkan!

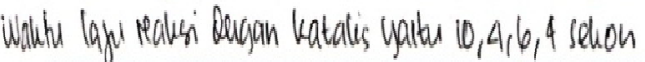

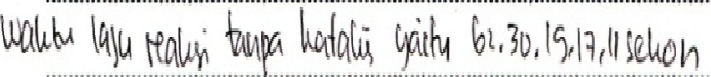

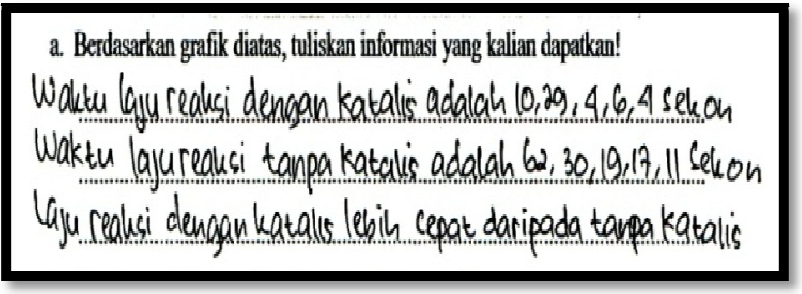

(b)

Gambar 5 Jawaban Siswa pada Tes Keterampilan Metakognitif Planning Skils: (a) Skor 2; dan (b) Skor 3

Nilai rata-rata hasiltesketerampilan metakognitif planning skills selama empat kali pertemuan dan didukung juga oleh data inventori metakognitif telah memiliki kategori baik. Hal tersebut menunjukkan bahwa penerapan model pembelajaran Learning Cycle $7 E$ dapat melatih keterampilan metakognitif planning skills.

Keterampilan metakognitif memantau meliputi berulang kali membaca materi sampai seseorang dapat memahami, menggunakan kamus untuk mencari kata-kata sulit, menyoroti teks yang dianggap penting, menggunakan grafik organizer (menulis ulang catatan, membuat tabel dan diagram, dll) konsultasi rujukan, meninjau solusi untuk sampel masalah, meninjau tes kembali, pemecahan masalah tambahan, memeriksa kemajuan terhadap tujuan atau list yang telah dilakukan, meminta teman atau orang lain untuk membantu atau sebagai mitra belajar [7]. Pada penelitian ini, keterampilan metakognitif memantau yang dilatihkan kepada siswa yaitu meninjau solusi untuk sampel masalah (meriview hasil tes atau praktikum) dan memecahkan masalah tambahan. Tes keterampilan memantau tersebut dinilai dengan skor 0-3 dengan kriteria tertentu sesuai dengan rubrik penilaian. Jawaban siswa pada tes keterampilan metakognitif monitoring skills ditunjukkan pada Gambar 6.

b. Bagaimana hubungan katalis dengan laju reaksi?

Katalis dapat menurunkan energi glstivasi sehinoga

laiu reaksi berralan cepat

(a) 


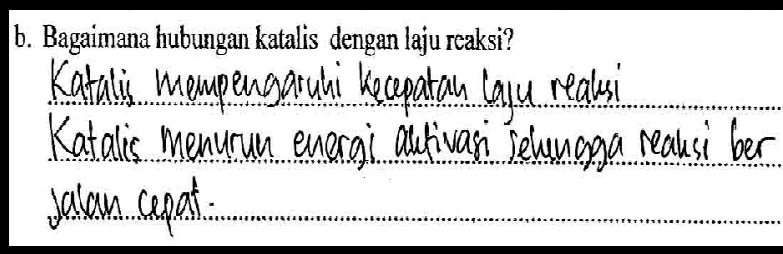

(b)
Gambar 5 Jawaban Siswa pada Tes Keterampilan Metakognitif Monitoring Skils: (a) Skor 1; dan (b) Skor 3

Untuk monitoring skills telah memperoleh kategori baik dan sangat baik. Data keterampilan metakognitif memantau siswa juga didukung oleh angket inventori metakognitif dengan kategori baik dan sangat baik pula.Temuan tersebut memberikan fakta bahwa penerapan model pembelajaran Learning Cycle $7 E$ dapat melatih keterampilan metakognitif monitoring skills.

Evaluating skills siswa meliputi memeriksa terhadap tujuan tertulis atau untuk melakukan daftar jika semuanya terjadi, berkaca pada strategi studi mengidentifikasi apa yang bekerja dan tidak bekerja, menilai strategi belajarberdasarkan salah satu kinerja pada tes atau kualitas tugas yang diserahkan, menilai bagaimana strategi studi dapat diterapkan dalam konteks pembelajaran lainnya, menghargai diri sendiri setelah belajar atau menyelesaikan tugas $[7,13]$. Pada penelitian ini, evaluating skills siswa yang dilatihkan yaitu refleksi pada strategi belajar dan menilai strategi belajar.Tes evaluating skillstersebut dinilai dengan skor 0-3 dengan kriteria tertentu sesuai dengan rubrik penilaian. Jawaban siswa pada tes keterampilan metakognitif evaluating skills ditunjukkan pada Gambar 6.

Tuliskan alasam dari simpulan yang telah kalian ambil! Sulu yaug tuggi menyeloghan fartinel bergerah lebch cepat sehmoga musah untuh teragi tumbenan antar earbihes

(a)

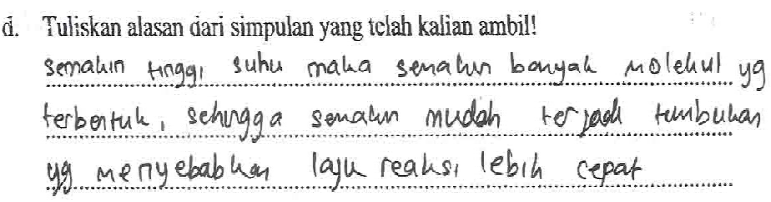

(b)

Gambar 6 Jawaban siswa pada tes keterampilan metakognitif evaluating skills: (a) skor 1; dan (b) skor 3

Evaluating skills telah memperoleh kategori baik dan sangat baik. Keterampilan metakognitif evaluating skills siswa didukung juga oleh data angket inventori metakognitif dengan kategori baik. Temuan tersebut memberikan fakta bahwa penerapan model pembelajaran Learning Cycle $7 E$ dapat melatih keterampilan metakognitif evaluating skills.

\section{SIMPULAN DAN SARAN}

Berdasarkan hasil dan pembahasan, di dapat simpulan sebagai berikut.

1. Nilai Keterlaksanaan sintak model pembelajaran Learning Cycle $7 E$ selama empat kali pertermuan yaitu 100,00; 100,$00 ; 100,00 ; 84,38 ; 62,50 ; 78,13$; dan 87,50 dengan kriteria baik dan sangat baik.

2. Keterampilan metakognitif berada pada kategori baik sangat baik dengan nilai ratarata selama empat kali pertemuan yaitu: planning skills sebesar 3,19; 3,15; 3,41; dan 3,48 ; monitoring skill sebesar 2,70; 3,19; 3,37; dan 3,52; dan evaluating skills sebesar 2,30; 2,98; 3,32; dan 3,61.

3. Keterampilan metakognitif siswa berdasarkan inventori metakognitif berada pada kategori baik dan sangat baik dengan nilai rata-rata selama empat kali pertemuan yaitu: planning skills sebesar 3,05; 3,12; 3,22 ; dan 3,44; monitoring skill sebesar 3,$04 ; 3,19 ; 3,23$; dan 3,50: dan 3,09; 3,17; 3,19 ; dan 3,44 .

Saran yang diberikan berdasarkan hasil penelitian ini adalah sebelum guru menerapkan model pembelajaran Learning Cycle $7 E$, sebaiknya melakukan manajemen waktu karena mengingat banyaknya fase pada sintaks model pembelajaran Learning Cycle 7E.Keterampilan metakognitif evaluating skillssiswa seharusnya dilatihkan lebih optimal lagi, agar dapat maksimal. 


\section{DAFTAR PUSTAKA}

[1]Sanjaya, Wina. (2013). Strategi Pembelajaran (Berorientasi Standar Proses Pendidikan). Jakarta: Prenada Group

[2] Permendikbud. (2016). Permendikbud Nomor 24 tahun 2016 tentang Kurikulum 2013 Sekolah Menengah Atas/Madrasah Aliyah. Jakarta: Debdikbud.

[3] Eggen dan Kauchak. (2012). Strategi dan Model Pembelajaran. Jakarta: Indeks.

[4] Flavell, John H. (1979). Metacognitive and Cognitif Monitoring. American Psichological Association, Inc Stanford University.

[5] Livingstone, Jennifer A. (1997). Metacognition: An Overview. (online), http://gse.buffalo.edu/fas/shuell/cep5 64/metacog.htm.Diakses pada 30 Maret 2016.

[6] Suherman, dkk. (2001). Strategi Pembelajaran Matematika Kontemporer. Bandung: Jurusan Pendidikan Matematika UPI.

[7] Pulmones, Richard. (2007). Learning Chemistry in a Metacognitive Environment, (Online), The Asia PacificEducation Researcher Vol. 16 No. 2. (www.dlsu.edu.ph/research/journals/taper /pdf/200712/pulmones.pdf. diakses pada tanggal 16 Februari 2016)

[8] Jannah, Anissatul dan Azizah, Utiya. (2012). The Development Of Chemistry Worksheet Bilingual With Learning Cycle 7-E Orientation In The Reaction Rate Topic As Supporting Learning For Pioneering International Senior High School. Unesa Journal of Chemical Education, ISSN: 2252-9454. Vol. 1, No. 1, pp.17-24 Mei 2012.

[9] Eisenkraft, Arthur. (2003). Expanding the 5E Model. The Science Teacher (Online), Vol. 70, Nomor 6. http://its-abouttime.com/htmls/ap/eisenkrafttst. pdf. Diakses pada tanggal 27 Maret 2016.

[10] Rofi'ah, Faridatur dan Azizah, Utiyah. (2014). Pengembangan Lembar Kegiatan Siswa Berorientasi Learning Cycle 7-E pada Materi Pokok Laju Reaksi untuk Melatihkan Keterampilan Proses Sains. Unesa Journal of Chemical Education
ISSN: 2252-9454 Vol 3, No 2, pp.99-105, May 2014.

[11] Sudjana, Nana. (2006). Penilaian Hasil Proses Belajar Mengajar. Bandung: PT. Remaja Rosdakarya.

[12] Dasna, I Wayan dan Sutrisno. (2005). Model-model Pembelajaran Konstruktivistik dalam Pengajaran Sains/Kimia. Malang: FMIPA Kimia.

[13] Mu'minin, Siti Kholil Fatkhul dan Azizah, Utiya. (2014). Keterampilan Metakognitif Siswa Melalui Model Pembelajaran Inkuiri Pada Materi Asam Basa Di SMAN 1 Pacet Kelas XI. Unesa Journal of Chemical Education, ISSN: 2252-9454. Vol. 2, No. 2, pp.67-74 Mei 2014. 